\title{
Nodular skin problems encountered in a first-opinion equine clinic
}

\author{
Ellen J. van der Zaag' and Marianne M. Sloet van Oldruitenborgh-Oosterbaan ${ }^{2}$ \\ Veterinary Clinic "De Delta", Maasland' and Department of Equine Sciences, Faculty of Veterinary Medicine, Utrecht University², The Netherlands
}

\begin{abstract}
Summary
Over an eight year period (2004-2011) 68 horses with nodular skin disease were diagnosed with 70 tumour like skin lesions. Diagnoses of the 70 nodular lesions were based on clinical features (5), cytology of fine needle aspirates(4), histological examination of either a biopsy or a complete surgical specimen (59) or on a combination of cytology and histology (2). Fifty-nine (84\%) of the nodules proved to be genuine tumour like lesions and eleven (16\%) were different forms of localised inflammatory dermatitis. Owners (93\%) were very supportive of the need to perform histological or cytological investigations (65/70). Sarcoid was the most common nodular lesion (21) followed in order of occurrence by; melanoma (8), squamous cell carcinoma (8), nodular necrobiosis (7), mastocytoma (3), papilloma (2), maligne lymphoma (2), fibroma (2), naevus (1), botryomycosis (1), calcinosis circumscripta (1), collagen tumour (1), follicular hyperplasia (1) and follicular cyst (1). In the present study there was no breed predilection and the mean age of the group was 10.8 year (range 3-23 years). Melanoma occurred in $62.5 \%$ of the grey horses (5/8). Nodular necrobiose was only diagnosed in $10 \%$ of the cases, because when the nodule was noticed in the girth or saddle region no therapy was performed. Melanoma, nodular necrobiosis and sarcoids were in this relatively small study found on aspecific locations. In 70\% (49/70) the nodules were surgical removed with either sedation and local anaesthesia (38) or general anaesthesia (11). Most patients (60.6\%) were surgically treated at the practice (42/70). Of the 70 tumour-like lesions 61 lesions were scored for follow-up (for 8 cases no follow up was possible and one case had just started therapy); 64\% (39/61) of the horses had no recurrence of the skin lesion(s) and the owners considerd their horses to be cured. Satisfaction rate as judged by owners was even higher: $80 \%$ (49/61).
\end{abstract}

Keywords: skin tumour / skin nodule / skin lesion / dermatology / oncology / horse

\begin{abstract}
Noduläre Hautprobleme in einer privaten Pferdeklinik
Über einen Zeitraum von acht Jahren (2004-2011) wurde in einer privaten Überweisungsklinik bei 68 Pferden noduläre Hauterkrankungen mit 70 tumorähnlichen Veränderungen diagnostiziert. Die Diagnose wurde auf Grund des klinischen Erscheinungsbilds (5), Zytologie von Feinnadelaspiraten (4), histologischer Untersuchung entweder einer Biopsie oder eines kompletten chirurgischen Resekats (59) oder einer Kombination aus Zytologie und Histologie (2) gestellt. Neunundfünfzig (84\%) der Veränderungen waren nachgewiesenermaßen Neubildungen, bei 11 (16\%) handelte es sich um unterschiedliche Formen lokalisierter Dermatitis. In 65 (93\%) Fällen waren die Tierbesitzer kooperativ hinsichtlich der Gewinnung des Probenmaterial für die histologische oder zytologische Untersuchung. In den meisten Fällen (21) wurden Sarkoide festgestellt, gefolgt von Melanomen (8), Plattenepithelkarzinomen (8), nodulären Nekrobiosen (7), Mastozytomen (3), Papillomen (2), malignen Lymphomen (2), Fibromen (2) sowie Nävus (1), Botryomykose (1), umschriebene Kalzinose (1), Kollagentumor (1), follikuläre Hyperplasie (1) und follikuläre Zyste (1). In der vorliegenden Studie konnte keine Geschlechtsprädisposition nachgewisen werden. Das mittlere Alter der Patienten betrug 10,8 Jahre (3-23). Melanome traten in 5 von 8 Fällen bei Schimmeln auf. Noduläre Nekrobiose wurde nur in 10 Fällen diagnistiziert, weil keine Therapie durchgeführt wurde, wenn sich die Veränderung in der Sattellage befand. Melanome, noduläre Nekrobiose und Sarkoide wurden in dieser relativ kleinen Studie in unspezifischen Lokalisationen gefunden. In 70\% (49/70) der Fälle wurden die Tumoren chirurgisch entfernt, In 38 Fällen in Lokalanästhesie, in 11 Fällen unter Narkose. Die meisten Patienten $(60,6 \%)$ wurden in der Praxis behandelt (42/70). Bei 61 Patienten trat ein Rezidiv auf (8 Fälle konnten nicht nachverfolgt werden, in einem Fall war die Therapie bereits begonnen worden). In 64\% (39/61) der Fälle war die Therapie nach tierärztliche Befund erfolgreich. Die Erfolgsrate aus der Sicht der Tierbesitzer war höher. 80\% (49/61) schätzen die Behandlung als erfolgreich ein.
\end{abstract}

Schlüsselwörter: Hauttumoren / Hautknoten / Läsion / Dermatologie / Onkologie / Pferd

\section{Introduction}

In an equine first-opinion practice dermatological cases are often an intriguing challenge and in particular skin nodules are a common clinical presentation (Pilsworth and Knottenbelt 2005, Pilsworth and Knottenbelt 2007, White and Yu 2006, Williams 1995). Whilst many of the nodules have clinically distinctive features that allow an intuitive diagnosis, others are less characteristic and therefore offer greater diagnostic challenge. Nodules can be inflammatory or non-inflammatory. Infectious nodules include viral, bacterial, fungal and parasitic disorders. Amongst the non-infectious conditions immune mediated, neoplastic and reactive nodules are the main types encountered. Additionally single or multiple nodules in the skin may be occasionally associated with a more serious internal problem (Rees 2004). It is the responsibility of the first-opinion practitioner to consider all the potential differential diagnoses and then to use carefully chosen diagnostic procedures to achieve a definitive diagnosis.

Probably the most common nodular-like skin diseases in practice are nodular necrobiosis (also called eosinophilic granuloma) (Pilsworth and Knottenbelt 2005, Williams 1995) and skin tumours such as sarcoid and melanoma. The commonest skin tumour of horses is the equine sarcoid with the consistent reporting of extensive surveys of tumours in general and skin tumours in particular confirming this (Hewes 2006, Knottenbelt 2005, Pilsworth and Knottenbelt 2007, Rees 2004, Théon 2007). Sarcoids are known for their unpredictable behaviour and a variety of clinical presenta- 
tions (Knottenbelt 2005) and a biopsy can be justified where the diagnosis is not clinically irrefutable. Once the diagnosis is established the prognosis and the therapeutic options and their inherent limitations can be carefully explained to the owner. In contrast nodular necrobiosis has a far more predictable course: These lesions are often encountered in the saddle region and have a very characteristic clinical presentation. Biopsy of lesions in the saddle area may be problematic and so usually in this example, biopsy is neither necessary nor indicated (Knottenbelt 2009). Whilst the sarcoid can be a devastating disease that deteriorates rapidly, nodular necrobiosis is usually accepted as being a cosmetic nuisance - the owner may be more concerned than the horse. These two examples of common skin nodules demonstrated the need to reach a diagnosis and to use evidence based information to select the treatment and provide a prognosis.

This study set out to make a retrospective inventory of the nodular dermatological problems that needed either cytological or histological confirmation or surgical intervention in a first-opinion equine practice.

\section{Materials and methods}

Over an eight year period (2004-2011) 68 horses were diagnosed with nodular skin disease. In two horses two different nodular skin problems were found. A total of 70 lesions was therefore used in the study. The study group consisted of fortyone geldings and 27 mares. The breeds were: 20 Dutch Warmblood, 6 Haflinger horses, 5 Friesian horses, 5 Arabian horses, 3 cross bred 'Tinker' horses, 3 Quarter horses, 3 New Forest ponies and 23 horses of 19 different other breeds. The mean age was 10.8 year (range 3-23 year). These figures represent a cross section of the practice population.

Diagnoses of the 70 nodular lesions was based either on clinical features (5), cytology of fine needle aspirates or impression smears (4), histological examination of either a biopsy or a complete surgical specimen (59) or on the combination of cytology and histology (2).

\section{Results}

Diagnoses

Fifty-nine (84\%) of the nodules proved to be genuine tumour like lesions (Table 1) and eleven (16\%) were different forms of localised inflammatory dermatitis. In 93\% (65/70) of al lesions the diagnoses was confirmed by a pathologist. Sarcoid was the most common nodular lesion (21/59=36\%). This diagnosis was cases based on histology in twenty cases and on cytology in one case. Melanoma was found in 14\% (8/59) of the cases and the diagnoses was based on histology (5), on clinical appearance (2) or on cytology (1). Squamous cell carcinoma was identified in 14\% (8/59) of the cases based on histology (5 cases) and on the clinical appearance in three cases with lesions on the third eyelid. Malignant lymphoma and fibroma were both found in two cases (3.4\%) and all diagnoses were based on histological examination. Nodular necrobiosis was diagnosed in seven (12\%) cases based on histology (6) or cytology (1). Mastocytoma was identified histologically in three cases (5\%). Papilloma occurred in 3.4\% of the cases (2/59) and diagnosis was based exclusively on histology. The diagnoses of the last six cases were naevus (1), botryomycosis (1), calcinosis circumscripta (1), collagen tumour (1), follicular hyperplasia (1) and follicular cyst (1).

There were two horses with each two different lesions; one horse had a sarcoid and a papilloma and one horse had a sarcoid and nodular necrobiosis.

\section{Breeds and age}

In the present case study no breed predilection was evident. The mean age of the horses with mastocytoma (15.0 years old, range $11-17$ years) and squamous cell carcinoma (16.0 years old, range 12-23 years) seemed higher than the mean age of the whole group (10.8 years, range $3-23$ years). The mean age of the horses with sarcoids (9.4 years, range 4 - 21 years), melanoma (9.5 years, range $5-16$ years), nodular necrobiosis (8.3 years, range $3-14$ years) was comparable to the mean age of the whole group.

\begin{tabular}{|c|c|c|c|c|c|c|c|c|}
\hline & \multirow[t]{2}{*}{$\mathrm{n}$} & \multicolumn{2}{|c|}{ Gender } & \multicolumn{2}{|c|}{ Age years } & \multicolumn{2}{|c|}{ Diameter cm } & \multirow{2}{*}{$\begin{array}{c}\text { Surgery } \\
\text { percentage }\end{array}$} \\
\hline & & gelding & mare & mean & range & mean & range & \\
\hline equine sarcoids, & 21 & 16 & 5 & 9.4 & $4-21$ & 2.1 & $0.5-5$ & 67 \\
\hline melanoma & 8 & 5 & 3 & 9.5 & $5-16$ & 2.4 & $1-6$ & 88 \\
\hline squamous cell carcinoma & 8 & 5 & 3 & 16 & $12-23$ & 2.5 & $1-3.5$ & 100 \\
\hline nodular necrobiosis & 7 & 2 & 5 & 8.3 & $3-14$ & 1.4 & $0.5-3$ & 86 \\
\hline mastocytoma & 3 & 2 & 1 & 15 & $11-17$ & 1.7 & $2-1$ & 100 \\
\hline papilloma & 2 & 1 & 1 & 13.5 & $12-15$ & 0.5 & 0.5 & 50 \\
\hline maligne lymphoma & 2 & 1 & 1 & 18 & $14-22$ & 1 & $0.5-1.5$ & 50 \\
\hline fibroma & 2 & 2 & 0 & 15 & $10-20$ & 4.25 & $3.5-5$ & 50 \\
\hline naevus & 1 & 1 & 0 & 8 & - & 1 & - & 100 \\
\hline botryomycosis & 1 & 1 & 0 & 3 & - & 1 & - & 100 \\
\hline calcinosis circumscripta & 1 & 1 & 0 & 3 & - & 7.5 & - & 0 \\
\hline collagen tumour & 1 & 0 & 1 & 13 & - & $\#$ & $\#$ & 100 \\
\hline follicular hyperplasia/cyst & 2 & 1 & 1 & 14.5 & $11-18$ & 2.75 & $2.5-3$ & 100 \\
\hline total & 59 & 38 & 21 & - & - & - & - & - \\
\hline
\end{tabular}

\# = unknown 


\section{Colour}

Melanoma occurred in $62.5 \%$ of the grey horses (5/8). The three others were dun, bay and black respectively. Other nodular lesions were not specifically related to a coat colour.

\section{Location}

Two of the melanomas were located around the anus and perineal area and six were found on other locations including lower fore limb (2), hind limb, shoulder, trunk, and groin. Squamous cell carcinoma was diagnosed on the genital organs in four cases (50\%), on the third eyelid in three cases $(38 \%)$ and on the fore limb (12.5\%). The latter is an a-specific location, it started as a small wound and progressed in an ulcerating mushroom-like skin lesion and proved to be an squamous cell carcinoma. All three mastocytoma lesions were found on the mucocutaneous junctions; one each on the nose, lip and eyelid. Nodular necrobiosis was found in the axillary region under the girth in $57 \%$ of cases (4/7); the remaining three were each located on the nose under the nose band, on the shoulder and on the buttock. In the present study no specific location was identifiable for sarcoids which were distributed on the cheek, eyelid, ear, neck, breast, limbs, groin, preputium and scrotum. In eight-teen of sarcoid affected horses it concerned a single lesion, in three horses however there were at least two lesions at different sites.

\section{Tumour growth rate}

In two cases of the 59 tumour-like lesions (3.5\%) there was no information about the rate of tumour expansion. In $33 \%$ $(19 / 57)$ of the horses the growth was considered to be fast (nodule had grown obviously within weeks) and in 16\% (9/57) growth was reported to be slow or not apparent (static lesion, nodule had appeared insidiously over some years). In 29 cases $(51 \%)$ the growth rate was considered intermediate (nodule had appeared within months and had expanded slowly).

\section{Diameter of the lesions}

Most of the 59 tumour-like lesions were brought under the veterinarian's attention at an early stage (Table 1). The mean diameter of the sarcoids was $2.1 \mathrm{~cm}$ (range $0.5-5 \mathrm{~cm}$ ), melanoma $2.4 \mathrm{~cm}$ (range 1-6 cm), squamous cell carcinoma 2.5 $\mathrm{cm}$ (range 1-3.5 cm), nodular necrobiosis $1.4 \mathrm{~cm}$ (range 0.5$3 \mathrm{~cm}$ ) and mastocytoma $1.7 \mathrm{~cm}$ (range 2-1 cm). The largest lesion was the calcinosis circumscripta of approximately 7.5 $\mathrm{cm}$ in diameter.

\section{Therapy}

In $70 \%(49 / 70)$ the nodules were surgically removed with either sedation and local anaesthesia (38) or general anaesthesia (1 1). In 10\% (7/70) of the cases no therapy was undertaken (one fibroma, one melanoma, one dermatitis, one nodular necrobiosis, one papilloma and two sarcoids). In 11\% $(8 / 70)$ of the cases the lesions were treated topically; six of these were dermatitis cases, one diagnosed maligne lymphoma and one sarcoid.

In two horses (dermatitis and calcinosis cicumscripta) a systemic therapy of oral prednisolone was used. BCG therapy was used in four only sarcoid affected horses (two times as single therapy ones as complementary therapy after surgery and ones in combination with cryosurgery). Cryosurgery was used in two horses diagnosed sarcoid (ones as a single therapy and ones in combination with BCG) and in one horse with melanoma after surgical debulking of the tumour. Cisplatin beats were used as complimentary therapy after surgical intervention in two horses with a perineal melanoma and one horse with a sarcoid in the eyelid.

In the sarcoid cases eleven (52\%) times the owner and surgeon chose for treatment with sedation and local anaesthesia, in three cases (14\%) was decided for treatment under general anaesthesia, in four cases (19\%) for treatment with BCG and/or cryosurgery, in one horse topical therapy (acyclovir) was preferred and two owners preferred no therapy. In case of melanoma $88 \%(7 / 8)$ were treated surgically of which three horses were operated under general anaesthesia and one horse had no treatment. The eight horses diagnosed with squamous cell carcinoma were all treated surgically of which only two were operated in theatre. The seven horses diagnosed with nodular necrobiosis; six were operated under sedation with local anaesthesia and one owner preferred no therapy. All three horses with mastocytoma had surgical intervention. Both papilloma (2) and fibroma (2) were operated on in one case and had no therapy in the other. In two horses diagnosed with maligne lymphoma; one preferred no therapy and one was operated in theatre. Other single diagnosed tumours see table 1.

\section{Location for surgery}

Most patients were surgically treated at the practice $60.6 \%$ $(42 / 70)$, twenty-two lesions (31\%) at home and six (8.4\%) at the University Equine Clinic. Of the latter six, five were sarcoids and the therapy of choice was BCG and/or cryosurgery and one melanoma was treated with a combination of surgery and cryosurgery.

\section{Follow-up and recurrence}

Of the 70 initial lesions, 61 lesions were available for followup and scored for recurrence. No information was available for 9 lesions because in 8 cases the owner could not be reached and in one recently diagnosed sarcoid the therapy had just started. In $64 \%$ (39/61) of the cases the owner considered to horse to be cured meaning that the nodule or lesion was not visible anymore. In 16\% (10/61) there was no marked difference in appearance according the opinion of the owner and in 20\% (12/61) the problem was considered to have returned. Considering the sarcoids 50\% (10/20) showed no recurrence after treatment, 20\% (4/20) stayed unchanged and $30 \%(6 / 20)$ had a recurrence. In case of melanoma (8) two owners had not been reached and 6 horses had no recurrence. Squamous cell carcinoma $87.5 \%$ (7/8) surprisingly had no recurrence, only one patient had a recurrence and was finally euthanized. Of the nodular necrobiosis cases $71 \%$ 
(5/7) had no recurrence, and two stayed unaltered. In case of mastocytoma (3) one patient showed no recurrence and two owners have not been reached. The four horses diagnosed with maligne lymphoma (2) and papilloma (2) were 100\% successful. One of the two fibroma was treated successfully while the owner of the other case could not be contacted.

\section{Follow-up and satisfaction of the owner}

Considering the owner's satisfaction for the 61 lesions where evaluation was possible 80\% (49/61) considered the outcome of the treatment to be satisfying, seven owners (12\%) considered the outcome to be unsatisfying, five owners (8\%) were ambivalent. In case of the sarcoids $70 \%$ (14/20) of the owners were satisfied with the outcome. In all other cases the follow-up with reference to recurrence and the owners satisfaction were comparable.

\section{Discussion}

In a retrospective study by Valentine (2006) 538 neoplasms were identified, sarcoids, squamous cell carcinoma, melanocytic tumours, papillomas and mast cell tumours were the most common neoplasms. This is in accordance with the findings of the present study. Other studies by Hewes at al. (2006) included 56 horses; sarcoids, melanomas, squamous cell carcinomas and fibrosarcomas were the most encountered neoplasms. In the survey of Théon et al. (2007) 549 horses revealed as most common cutaneuos tumour; sarcoids, sqaumous cell carcinomas, soft tissue sarcomas, lymphomas and melanomas. Nodular necrobiosis is considered to be non neoplastic and therefore not screened in these surveys.

In $70 \%(49 / 70)$ of all the nodules the therapy of choice was surgery either with local anaesthesia or with general anaesthesia. If only the real nodular like lesions are considered this percentage is $76 \%$. The present study shows that most owners were motivated to request removal of tumour-like skin lesions immediately because they were suspicious of a possible malignant process. Owners were also very supportive to allow histological or cytological investigations (93\%) and were aware of the implications when this was not done. This may relate to the manner of owner communication and emphasis the need to communicate effectively prior to the procedure. Owners can make an informed decision on whether they want to pay for histology based on the logical information provided by the veterinarian. If the veterinarian is motivated to establish a real histological diagnosis most owners will also understand the importance of a true diagnosis and thus a more reliable prognosis. Only a tentative clinically based diagnosis was made in two cases of suspected perineal melanoma and three cases of suspected squamous cell carcinoma of the third eyelid. These diagnoses were considered to be clinically justifiable. Nevertheless additional information could have been derived from a histological examination as clinical pathology (histology) is often more important for establishing margins of excision and the degree of cell differentiation and replication / mitotic rate malignancy of a particular tumour type rather than just the basic diagnosis.

As might be expected dermatitis lesions were treated medically rather than surgically. In some of the relatively small nodules there was no therapy performed after excisional biopsy had been performed as the whole nodule was removed during the surgical procedure.

Surgery under local anaesthesia and sedation was the favoured therapy in 54\% (38/70) of the cases and had a no recurrence rate $66 \%$ (25/38). Most owners are apprehensive when a horse is operated under general anaesthesia and prefer local anaesthesia. Costs (insurance) may also play a role in this decision.

Concerning the surgery with local anaesthesia and sedation, $74 \%$ (28/38) was performed at the practice clinic, $26 \%$ $(10 / 38)$ was performed at the owners premises or in their stable. The high percentage at the equine clinic was largely due to the preference of the surgeon. Surgery under the more controlled conditions of the clinic was viewed as preferable especially when the temperament of the horse or the location of the lesion introduced possible complications.

Follow-up of the horses (total 61) showed a marked difference between recurrence and satisfaction of the owner. Sixtyfour per cent $(39 / 61)$ of the lesions showed no reoccurrence while $80 \%(49 / 61)$ of the owners were satisfied with the end result. This difference is based on the fact that in some cases the lesion was not cured but the owner was satisfied with the incomplete success such as a benign tumour. Satisfaction of the owner is a very subjective parameter and maybe not reliable for statistics.

In the literature nodular necrobiosis is usually regarded as the most common non-neoplastic nodular disease (Pilsworth and Knottenbelt 2005, White and Yu 2006, Williams 1995)) and sarcoids the most common neoplastic skin condition (Knottenbelt 2005, Pilsworth and Knottenbelt 2007, Rees 2004, White and $Y_{U}$ 2006). In the present study sarcoids were the most frequently diagnosed skin masses (21/70).

Sarcoids are notoriously difficult to remove surgically (Brostrom 1995) and often reoccur at the site of excision. Therefore the choice of therapy is debateable and there are many suggested treatments (Hewes et al. 2006, Martens et al. 2001, Pilsworth and Knottenbelt 2007, Théon et al. 2007, White and Yu 2006). In the present study the majority of cases were diagnosed with sarcoid and 67\% (14/21) were surgically treated either under local or general anaesthesia. Of these patients $50 \%$ had a no recurrence but nevertheless $64 \%$ of the owners considered the surgical intervention to be satisfying. Surgical excision according to the literature (Rees 2004 and White and $Y_{U}$ 2006) had a slightly higher recurrence rate of $50 \%-64 \%$ and are therefore often combined with other therapies. Martens et al. (2001) had a successful outcome of $82 \%$ after conventional excision, but rigorous measures were taken to avoid autoinoculation and to ensure a wide margin of normal skin. The disadvantage of surgery under local anaesthesia in this study is that probably less attention is given to ensure wide margins excising the tumour. Furthermore five sarcoids (24\%) were treated with BCG and/or cryosurgery of which three were successful according to the owner. One case was recent and no follow-up was therefore available. Cisplatin was used only in one case as complimentary therapy after surgery of the eyelid and had a good outcome. In all other cases just one therapy was applied. 
Nodular necrobiosis was only diagnosed in seven cases (10\%) in the present study. This difference compared to literature is probably caused by the fact that in cases of nodular necrobiosis in the saddle or girth region the attending veterinarian made the diagnosis on clinical appearance and no biopsy and therapy was performed. Surgical intervention however is a therapeutic option (Rees 2004, Pilsworth and Knottenbelt 2005) but the result can sometimes be disappointing (Sloet and Knottenbelt 2001) as nodular necrobiosis in these areas can reappear quickly and the horse cannot be used for a longer period. Therefore glucocorticoids are advocated as the principal means of treating these lesions (Rees 2004, White and Yu 2006, Williams 1995). The fact that nodular necrobiosis on these predilection places was not biopsied or treated possibly explains why in the present study all nodular necrobiosis cases occurred at less common locations and surgery was successful.

Melanoma are most commonly seen around the anus, vulva, tail, and parotid region (Moore et al. 2012, Rees 2004, Rowe et al. 2004, Sloet and Knottenbelt 2001) but also occur in the lips, jugular furrow, subauricular lymph nodes (Moore et al. 2012, Pilsworth and Knottenbelt 2006) and eyelids (Pilsworth and Knottenbelt 2006, Seltenhammer et al. 2003). In the present study only two horses showed a melanoma at one of the predilection sites (perineum); both were grey horses. In these two cases the diagnosis was based solely on clinical appearance and surgical excision of the lesions was successful. In the other six melanoma cases the location was either on the limbs or the trunk. The reason for biopsy was a combination of an atypical appearance, an atypical location and the fact that three of these horses were not grey. Rowe et al. (2004) suggest that excision of dermal melanomatosis in horses is a reasonable treatment option. In our limited study six horses were successfully operated. Only three melanomas on the limb were operated under general anaesthesia because of the size of the lesion and the relative lack of skin on the distal part of the limb.

According to van den Top et al. (2008) the success of treatment, complete removal and prevention of recurrence of squamous cell carcinoma in male horses is $55.7 \%$. In the present retrospective study squamous cell carcinoma at different locations had a recurrence rate of $87.5 \%$ (7/8). Seven neoplasms were successfully removed surgically using conventional sharp surgical techniques; two tumours were located at the penis (operated under general anaesthesia) one on the preputium, one at the upper limb and three were third eyelid tumours. The success of the third eyelid tumours is in agreement with Labelle et al. (2011). The surgical margins were not checked in all cases, especially the third eyelid tumours. Only in one penile tumour there was incomplete removal however there is no recurrence up till now (2 years). One patient with a labial carcinoma tumour of the vulva was successfully operated and had clean margins according the pathologist. Nevertheless after two years it grew excessively and the horse was finally euthanized because of this relapse.

This inventory of nodular skin problems in a primary practice provides a rough guide to the prevalence of the various conditions that might be encountered. The overall outcome for the various selected treatments is broadly comparable to previous literature reports and illustrates that good outcomes can be achieved in a primary practice for most if not all the con- ditions that cause nodular skin disease. Early recognition and treatment of tumour-like skin lesions is clearly a major factor in the prognosis of most of the tumour condition.

\section{References}

Broström H. (1995) Equine Sarcoids: A clinical, epidemiological and immunological study. PhD Thesis, University of Uppsala, Stokkholm, Sweden pp. 9-69

Hewes C. A., Kenneth E. and Sullins E. (2006) Use of cisplatin-containing biodegradable beads for treatment of cutaneous neoplasia in equidae: 59 cases (2000-2004). J. Am. Vet. Med. Assoc. $10,1517-1622$

Knottenbelt D. C. (2005) A Clinical Classification of the Equine Sarcoid. Clinical Techniques in Equine Practice 4, 278-295

Knottenbelt D. C. (2009) Eosinophilic dermatitis with collagen necrosis/eosinophilic granuloma/collagenolytic granuloma. In: Pasco's Principles and practice of equine dermatology. 2 nd Ed. Saunders Elsevier, Edinburgh, pp. 292-294

Labelle A. L., Metzler A. G. and Wilkie D. A. (2011) Nictating membrane resection in the horse: a comparison of long-term outcomes using local vs. general anaesthesia. Equine Vet. J. Suppl. 40, 42-45

Martens A., De Moor, Vlaminck L., Pille F. and Steenhaut M. (2001) Evaluation of excision, cryosurgery and local BCG vaccination for the treatment of equine sarcoids. Vet. Rec. 22, 665-669

Moore J. S., Shaw C., Shaw E., Buechner-Maxwell V., Scarratt W. K., Crisman M., Furr M. and Robertson J. (2012) Melanoma in horses: Current perspectives. Equine Vet. Educ. online 17 jan

Pilsworth R. C. and Knottenbelt D. (2007) Skin Disease Refresher, Equine sarcoids. Equine Vet. Educ. 5, 260-262

Pilsworth R. C. and Knottenbelt D. (2006) Skin disease refresher, melanoma. Equine Vet. Educ. 5, 228-230

Pilsworth R. C. and Knottenbelt D. (2005) Skin disease refresher, nodular collagen necrosis (collagenolytic granuloma). Equine Vet. Educ. 5, 228-229

Rees C. A. (2004) Disorders of the skin. In: Equine Internal Medicine, Saunders, Elsevier Philadelphia, 2, 667-720

Rowe E. L. and Sullins K. E. (2004) Excisions as treatment of dermal melanomatosis in horses: 11 cases (1994-2000). J. Am. Vet. Med. Assoc. 1, 94-96

Seltenhammer M. H., Simhofer H., Scherzer P., Curik I., Sölkner J., Brandt S. M., Jansen B., Pehamberger H. and Eisenmenger E. (2003) Equine melanoma in a population of 296 grey Lipizzaner horses. Equine Vet. J. 2, 153-157

Sloet van Oldruitenborgh-Oosterbaan M. M. and Knottenbelt D. C. (2001) The Practitioners Guide to Equine Dermatology, Uitgeverii Libre BV, Leeuwarden, 28-56

Théon A. P., Wilson W. D., Magdesian K. G., Pusteria N., Snyder J. R. and Galuppo L. D. (2007) Long-term outcome associated with intratumoral chemotherapy with cisplatin for cutaneous tumors in equidae: 573 cases (1995-2004). J. Am. Vet. Med. Assoc. 10, $1506-1513$

Valentine B. A. (2006) Survey of equine cutaneous neoplasia in the Pacific Northwest. J. Vet. Diagn. Invest. 1, 123-126

Van den Top J. G. B., Heer de N., Klein W. R. and Ensink J. M. (2008) Penile and preputial squamous cell carcinoma in the horse: $A$ retrospective study of treatment of 77 affected horses. Equine Vet. J. 6, 533-537

White S. D. and Yu A. A. (2006) Equine Dermatology. II. Nodules, Lumps and Bumps. Proceedings of 52 Annual Convention of American Association of Equine Practitioners, San Antonio, TX, USA Dec 2-6, 2006

Williams P. D. (1995) Lumps, bumps and swellings - a clinical approach to diagnosis. Equine Vet. Educ. 6, 300-303

Ellen van der Zaag

Veterinary Clinic "De Delta", Maasland, The Netherlands

Foppenpolder 1

3755 EA Maasland

The Netherlands

ejvanderzaag@hotmail.com 